\title{
Occupational Contact Dermatitis: An Individualized Approach to the Worker with Dermatitis
}

\author{
Marie-Claude Houle $^{1} \cdot$ D. Linn Holness ${ }^{1} \cdot$ Joel DeKoven $^{1}$ (I)
}

Accepted: 9 July 2021 / Published online: 14 September 2021

(c) The Author(s), under exclusive licence to Springer Science+Business Media, LLC, part of Springer Nature 2021

\begin{abstract}
Purpose of Review To provide an up-to-date, customizable approach to the worker presenting with dermatitis.

Recent Findings Occupational contact dermatitis (OCD) is often a result of combined allergic, irritant, and endogenous factors. Potential causes of OCD can be categorized in 3 main groupings: workplace materials, personal protective equipment, and skin care. Although patterns of dermatitis may provide some indication of the etiological factor(s), patch testing remains essential in the diagnosis of allergic OCD. Management of OCD may require changes in workplace practices to reduce worker exposure to the causative agents and improve skin care practices.

Summary OCD is a multifaceted condition with significant consequences for affected workers and their families, employers, and insurers. A methodical and individualized approach to the patient with OCD should ensure timely and accurate diagnosis(es).
\end{abstract}

Keywords Irritant contact dermatitis $\cdot$ Occupational contact dermatitis $\cdot$ Patch testing

\section{Introduction}

Occupational contact dermatitis (OCD) encompasses a vast array of clinical presentations and underlying causes. Each worker is unique, having specific job tasks to accomplish as well as personal factors, such as atopic tendencies, that need to be considered. Thus, management of workers suffering from OCD must account for individual circumstances.

Although this may seem like a daunting task for the busy clinician, occupational dermatology can prove to be a very rewarding practice. The purpose of this review is to provide an up-to-date, customizable approach to the worker presenting with dermatitis.

\section{Occupational Contact Dermatitis}

Contact dermatitis can be defined as an inflammatory skin condition, usually eczematous in nature, induced by exposure to an external irritant or allergen. Allergic

This article is part of the Topical Collection on Contact Dermatitis

Joel DeKoven

joel.dekoven@utoronto.ca

1 Toronto, Canada contact dermatitis (ACD) and irritant contact dermatitis (ICD) are distinct entities. ICD can be defined as a non-immunological, non-specific reaction of the skin to an irritant. However, this definition is too simplistic. By damaging epidermal skin cells, an irritant causes a nonspecific immune response which will not confer protective immunity to the host [1]. ACD on the other hand is an adaptive immune response toward chemicals penetrating the skin. It is a type IV, delayed, or cell-mediated immunological reaction. ACD occurs in a two-phase process. Sensitization may occur on first exposure or at any time with subsequent exposure. Once sensitization is completed, elicitation will occur upon re-exposure [2]. OCD, either ICD or $A C D$, results from exposures found in the workplace.

Endogenous factors, such as atopic eczema, greatly influence susceptibility to irritation. Contact sensitization has been shown to develop in the skin recently damaged from trauma or irritation. This may explain why some workers have minimal skin issues for months to years then "suddenly" develop ACD [2].

OCD is the most common occupational skin disease and constitutes up to $30 \%$ of reported occupational diseases. The average incidence rate of registered OCD ranges from 0.5 to 1.9 cases per 1000 full-time workers per year [3]. There 
are a variety of sources of information about OCD and its causative agents [4]. Tables 2 and 3 list some of the common causes of OCD [5•,6-8]. Negative impacts of OCD include reduced function, quality of life, work disruption, and economic effects [4].

\section{Early Detection and Prevention}

Studies have demonstrated a significant time between onset of symptoms and seeking health care, an average of 8.6 months [9] to more than 30 months [10]. Workers' fear of job loss is a major factor in explaining this delay; many first attempt to treat their skin problem on their own before seeking help [11].

Delay in seeking care and in diagnosis often leads to longer exposure to the causative agent. This has been shown to correlate with poorer prognosis [4]. As early identification and management improves outcomes, screening to detect early disease would be desirable but is difficult to achieve in practice. A validated screening tool for hand dermatitis in health care workers has been developed as a self-administered questionnaire [12]. Limited information is available regarding its usability in other work environments.

\section{Approach to the Worker with Suspected Occupational Contact Dermatitis}

OCD is a multifactorial disease and is often a result of combined allergic, irritant, and endogenous factors. When a worker seeks care for suspected OCD, a methodical approach is necessary [13]. A complete occupational history including work exposure assessment must be conducted. Physical examination may also provide clues as to causative agent, but thorough investigations, including comprehensive patch testing to suspect workplace substances, are of paramount importance in identifying the correct diagnosis. A significant step in the management of OCD is establishing causality as this will influence the choice of preventive measures, the prognosis for successful return to current/modified work, and the outcome of workers' compensation adjudications. This is facilitated by the physician's acquisition of fundamental knowledge about the most common causes of OCD and familiarity with the industries that employ most workers in their communities.

\section{Occupational History}

A detailed exposure history is essential in the initial and continuing evaluation of the patient with suspected OCD [6]. A number of etiological factors may be present; the astute clinician must have a clear understanding of individual job tasks as well as types and routes of cutaneous exposures in the workplace. Table 1 lists the information that should be gathered from the occupational history $[6,14]$.

\section{Clinical Presentations}

OCD most commonly affects the hands, followed by the wrists, forearms, and face [15]. Still, the specific areas affected may vary depending on the type of contact triggering the dermatitis, the causative allergens, and whether the underlying mechanism is allergic, irritant, or both. Important aspects to consider are the possible routes of exposure. An irritant or allergen may come in contact with the skin through direct contact, aerosolized particles (airborne contact), transfer (from touching the face or genitalia for example), or even from a partner (connubial dermatitis). Although one cannot rely solely on clinical findings to identify the cause(s) of OCD, patterns of dermatitis may provide some indication of the etiological factor(s) (Figs. 1 and 2) [16].

Table 1 Occupational history elements

- Employer

Industrial sector

$\bigcirc$ Description of work site

$\bigcirc$ Approximate number of employees

$\bigcirc$ Presence of health and safety committee or resource person

Modified work available or already instituted

- Job title(s); number of jobs

$\bigcirc$ Number of years working at the job

$\bigcirc$ General description of work tasks

$\bigcirc$ Work schedule, including full-time, part-time and casual work

Materials contacted at work

- Obtaining safety data sheets (SDS)

- Personal protective equipment and preventive practices

$\bigcirc$ PPE provided by the employer

- Actual use of PPE

$\bigcirc$ Hand hygiene practices

Moisturizers or barrier cream use

- History of skin problem

History of atopy or other skin disease

Time of appearance of skin problem

Symptoms variation during days off or during vacation

$\bigcirc$ Days off work because of skin problem

$\bigcirc$ Skin care practices (over-the-counter and prescription treatments)

- Workers' compensation claim

- Hobbies and exposures outside the workplace

- Coworkers with similar issues 


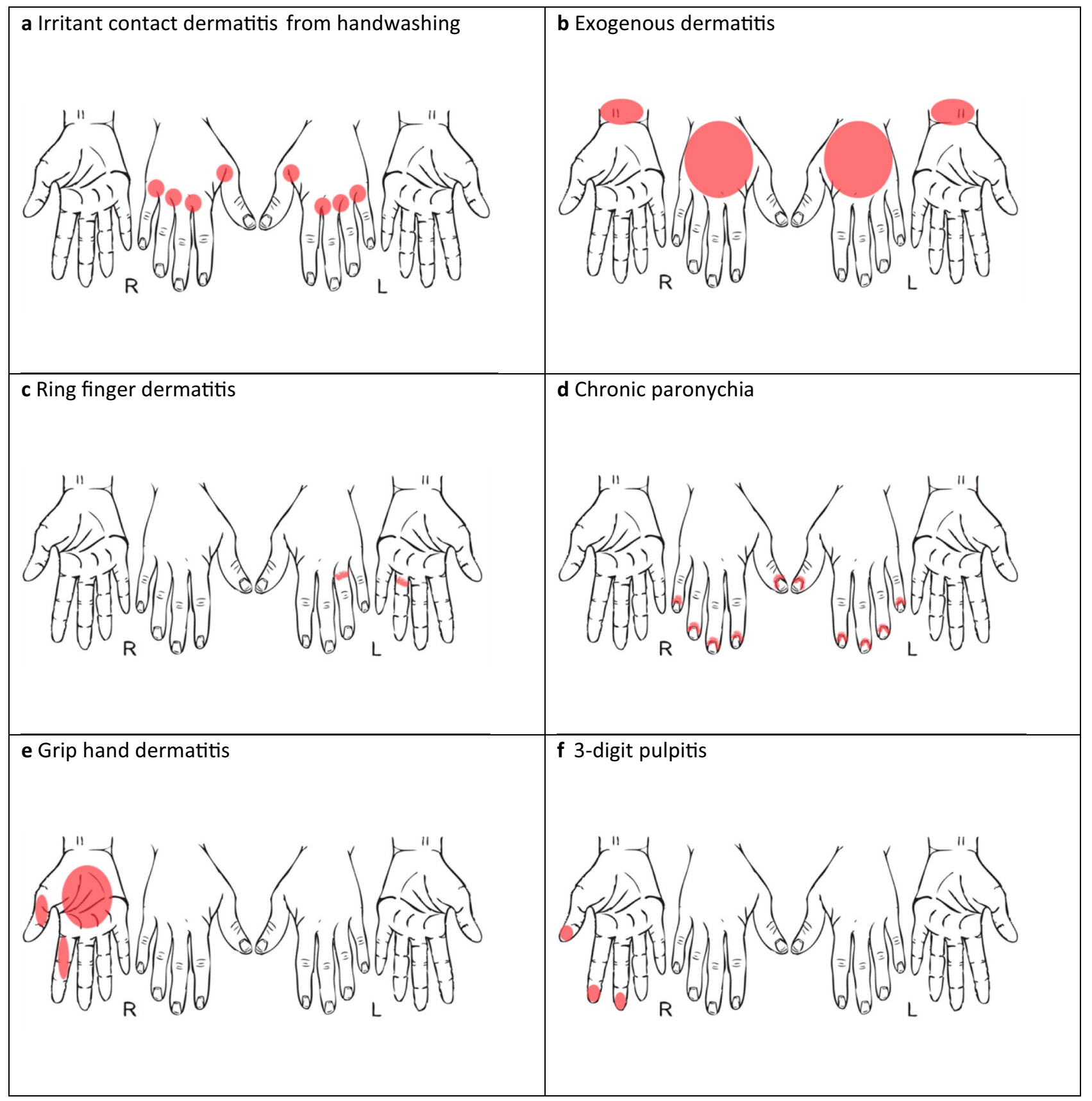

Fig. 1 Common clinical patterns of hand contact dermatitis: a irritant contact dermatitis from handwashing, b exogenous dermatitis, $\mathbf{c}$ ring finger dermatitis, $\mathbf{d}$ chronic paronychia, e grip hand dermatitis, and $\mathbf{f} 3$-digit pulpitis

Common clinical patterns of hand dermatitis are as follows:

a) Frequent hand washing will induce dermatitis to first appear on the interdigital areas (Fig. 1a). The interdigital space creates occlusion, increasing the irritant potential of the remaining water and soaps left on hands that have been inadequately rinsed and dried. b) A typical pattern of exogenous hand dermatitis will present with red and scaly plaques on the dorsal hands and inner wrists (Fig. 1b). This pattern is a common presentation for ACD to rubber accelerators in gloves, classically with a well-defined line of demarcation that extends to the outer edge of the cuff of the glove.

c) ACD to metals found in ring jewelry or ICD induced by trapped water under the ring will present with very localized dermatitis on the ring bearing finger (Fig. 1c). 


\begin{tabular}{|l|l|l|l|l|l|}
\hline $\begin{array}{l}\text { a Airborne } \\
\text { contact } \\
\text { dermatitis }\end{array}$ & $\begin{array}{l}\text { bPhotocontact } \\
\text { dermatitis }\end{array}$ & $\begin{array}{l}\text { c Rinse -off } \\
\text { contact } \\
\text { dermatitis }\end{array}$ & $\begin{array}{l}\text { d Face cream } \\
\text { contact } \\
\text { dermatitis }\end{array}$ & $\begin{array}{l}\text { e Periorbital } \\
\text { contact } \\
\text { dermatitis }\end{array}$ & $\begin{array}{l}\text { f Facial PPE contact } \\
\text { dermatitis }\end{array}$
\end{tabular}

Fig. 2 Common clinical patterns of face contact dermatitis: a airborne contact dermatitis, b photocontact dermatitis, $\mathbf{c}$ rinse-off contact dermatitis, $\mathbf{d}$ face cream contact dermatitis, e periorbital contact dermatitis, and $\mathbf{f}$ facial PPE contact dermatitis

d) Wet work may induce chronic paronychia, which is frequently aggravated by the habit of removing nail cuticles by the patient (Fig. 1d).

e) Grip hand dermatitis generally presents with hyperkeratotic plaques with mild or absent underlying inflammation in the areas of repeated friction (Fig. 1e).

f) Workers manipulating small objects may develop dermatitis of the first 3 digits, which may be of allergic or frictional (irritant) origin (Fig. 1f).

Common clinical patterns of facial dermatitis are as follows:

a) Airborne contact dermatitis classically presents with a diffuse facial dermatitis which may involve the upper eyelids and submental and retroauricular areas (Fig. 2a), helping to differentiate it from photocontact dermatitis. The beak sign (i.e., nasal ridge and/or tip sparing) may result from increased sebaceous gland concentration/ activity preventing penetration of the epidermal barrier by aerosolized, water-soluble irritants. It may also serve as an important clinical clue to airborne contact dermatitis [17].

b) Photocontact dermatitis will affect areas exposed to light, sparing the upper eyelids, nasolabial folds, and submental and retroauricular areas (Wilkinson's triangle). The distinction between photocontact and airborne dermatitis may be difficult to make [18].

c) Lateral facial dermatitis involving the pre-auricular areas, post-auricular areas, jaw lines, and/or lateral neck may be due to rinse-off hair products [19]. This will also affect the eyelids depending on the forward or backward rinse-off habits (Fig. 2b).

d) Contact dermatitis from face cream or make-up will predominantly affect the cheeks, forehead, and chin, but the areas affected may differ depending on the pattern of application (Fig. 2c). e) Goggles may produce a localized periorbital dermatitis (Fig. 2d).

f) Personal protective equipment such as face shields, masks, and protective glasses will induce dermatitis at their specific sites of contact (Fig. 2e).

\section{Causes of Occupational Contact Dermatitis}

When OCD is suspected, it is useful to categorize potential causes into 3 main groupings: workplace materials, personal protective equipment (PPE), and skin care.

\section{Workplace Materials}

Workplace materials include substances the worker contacts as part of the work practice and as part of work-related hand hygiene. General information about work products is obtained during the occupational history with further important details found through review of safety data sheets (SDS). Although often incomplete, the SDS provide a general inventory of the categories of products used at work, can help guide appropriate patch testing, and facilitate custom patch testing if deemed necessary. SDS for products provided for hand hygiene must also be reviewed and their labels consulted for ingredient lists.

\section{Allergens in Workplace Materials}

ACD develops with repeat exposure to chemical allergens. Workers may contact a potential allergen many times over many months without any problems before becoming sensitized and developing ACD. Usually, only one or very few workers will be affected.

The North American Contact Dermatitis Group (NACDG), a group of Canadian and US dermatologists who evaluate patients with suspected ACD using a standardized 


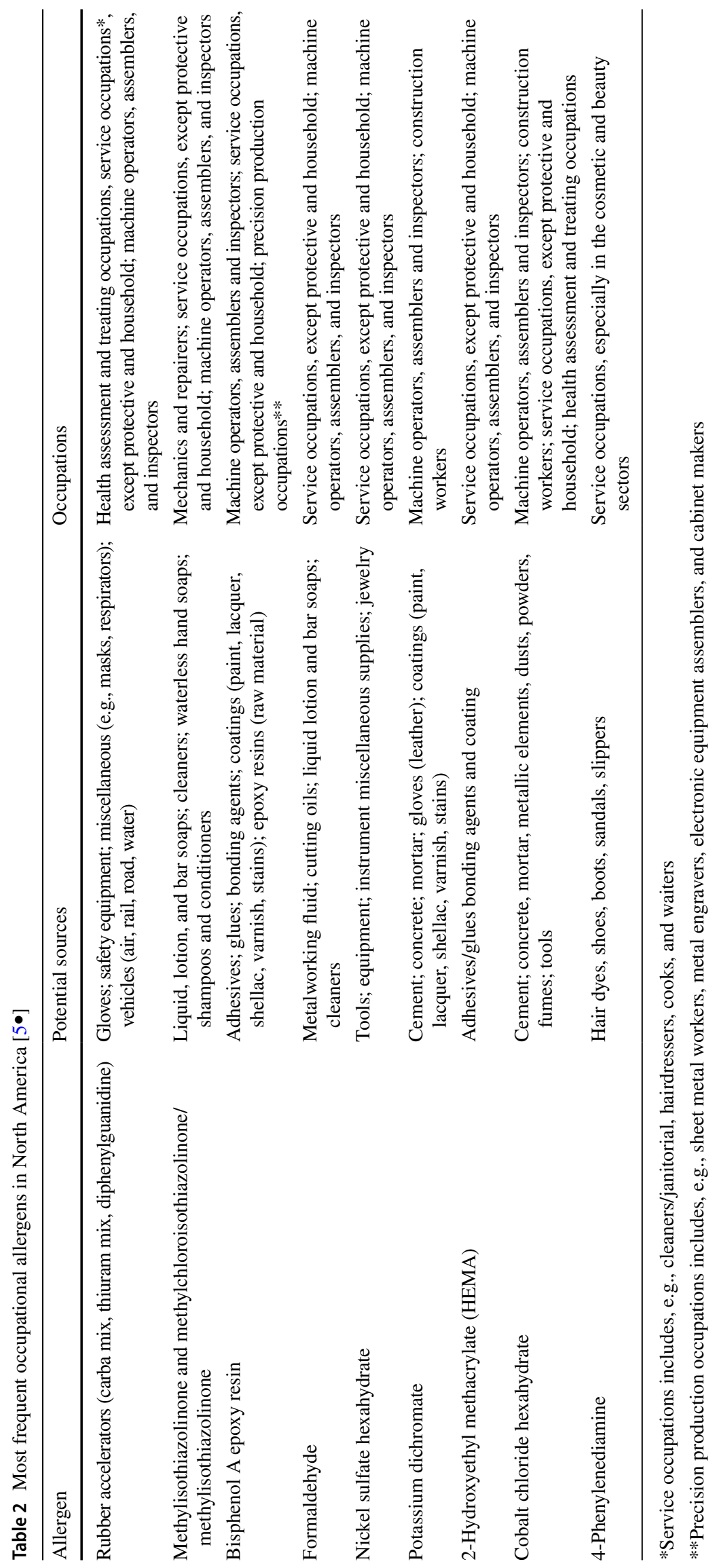


set of allergens, recently reported a retrospective analysis of OCD from 2001 to 2016, with a focus on ACD [5•]. The most common clinically relevant occupational patch test substances were rubber accelerators (carba mix, thiuram mix, and diphenylguanidine), methylisothiazolinone, bisphenol A epoxy resin, formaldehyde, nickel, potassium dichromate, 2-hydroxyethyl methacrylate, and cobalt (Table 2). Similarly, the European Surveillance System on Contact Allergies (ESSCA) network reported their results from 2000 to 2012 with the European baseline series for patients with OCD [20]. The allergens with the strongest occupational association were similar to the NACDG profile.

\section{Irritants in the Workplace}

When thorough patch testing does not identify a contact allergen, the diagnosis might then be ICD. Although susceptibility varies among individuals, given sufficient exposure to an irritant, anyone can develop ICD [7•]. The clinical spectrum of ICD is broad and often indistinguishable from ACD and other types of eczema [1].

High-risk occupations for the development of ICD include medical personnel, hairdressers, metalworkers, food workers, and construction and cement workers [7•]. Strong irritants such as alkalis, acids, and solvents may rapidly induce ICD. However, the most common type of ICD is caused by repetitive exposure to a weak irritant or wet work over a longer period of time [7•]. Table 3 lists the common irritants from the workplace [6-8]. It is important to note that many substances have irritant properties as well as allergic potential.

\section{Personal Protective Equipment}

Personal protective equipment (PPE) is of great value to prevent contact with environmental irritants, allergens, and/or microbial agents. However, PPE can also be the source of the problem, through the development of a contact allergy to one or more of its components or ICD through friction, pressure, or sweat.

Prolonged occlusion from rubber gloves has been defined as wearing gloves $>2 \mathrm{~h} /$ day or change of gloves $>20$ times/ day [8]. Prolonged glove wearing creates occlusion, preventing normal evaporation from the skin surface and resulting in an accumulation of moisture. Secondary elevated temperature and sweating can lead to increased skin $\mathrm{pH}$ and the induction of ICD [21]. Once the integrity of the skin barrier is breached, there is an increased risk of subsequent contact allergy to PPE, work substances, or topical treatment.

Facial PPE often induce ICD through friction and pressure and rarely may induce ACD [22]. Table 4 lists the potential allergens present in different PPE as well as mechanisms by which they may induce ICD.

\section{Skin Care}

Management of primary contact dermatitis may sometimes result in secondary contact dermatitis. Workers will try different topical remedies before seeking help, including topical antibiotics, moisturizers, and natural products. Topical corticosteroids or antifungals may also be prescribed. All of these have the potential to cause ACD to one or more of their constituents. This should be considered, particularly if the skin condition was noted to worsen with the use of some of these products [23]. Potential allergens include corticosteroid molecules, topical antibiotics, local anesthetics, and non-medicinal ingredients including preservatives, vehicles, emollients, and fragrances [24•]. Skin care may also be the cause of ICD.

\section{Investigating Workers with Possible Occupational Contact Dermatitis}

The gold standard in the workup of a worker with possible ACD is patch testing. A standard screening series of allergens is useful to detect most common allergens. A detailed NACDG analysis of OCD showed that $81.7 \%$
Table 3 Most common occupational irritants

\begin{tabular}{ll}
\hline Irritant & Sources \\
\hline Water & Wet work; frequent hand washing; hand disinfection \\
Work clothing & Rubber gloves; rough-textured and woolen clothing; occlusive footwear \\
Friction & metal tools, wood, coal, rock \\
Dust & Fiberglass; stone dust, chemical dusts, cement dust, sawdust \\
Antimicrobial chemicals & Detergents, soaps, cleansers, disinfectants, antiseptics \\
Oil products & Hydrocarbons-petroleum and oils \\
Metalworking fluids & Cutting oils; cooling fluids \\
Organic matter & Food; plants \\
Solvents & Gasoline, paint thinners \\
Acids and alkalis & Hydrocarbons-petroleum and oils \\
Environment & Cool air; low humidity; high humidity \\
\hline
\end{tabular}


Table 4 Potential allergens and mechanisms of irritation from personal protective equipment

\begin{tabular}{|c|c|c|}
\hline PPE & Potential allergens & Mechanisms of irritation \\
\hline Rubber gloves & Rubber accelerators & $\begin{array}{l}\text { Occlusion } \\
\text { Friction }\end{array}$ \\
\hline Leather gloves & Potassium dichromate, cobalt, textile dyes & $\begin{array}{l}\text { Friction } \\
\text { Concentration of irritants in } \\
\text { soiled gloves from work } \\
\text { substances }\end{array}$ \\
\hline Protective glasses & Rubber accelerators (nose or ear pads), adhesives & $\begin{array}{l}\text { Friction } \\
\text { Pressure }\end{array}$ \\
\hline Face shields & Rubber accelerators, adhesives & $\begin{array}{l}\text { Friction } \\
\text { Pressure }\end{array}$ \\
\hline Mask & $\begin{array}{l}\text { Rubber accelerators and antioxidants (IPPD**), metal wires (nickel and cobalt), adhesive } \\
\text { chemicals (methyldibromoglutaronitrile), formaldehyde, isocyanates (polyurethane })^{43}\end{array}$ & $\begin{array}{l}\text { Friction } \\
\text { Pressure } \\
\text { Occlusion }\end{array}$ \\
\hline Uniforms (clothing) & Formaldehyde resins, textile dyes & $\begin{array}{l}\text { Friction } \\
\text { Pressure (if tight tool belt) }\end{array}$ \\
\hline Boots & $\begin{array}{l}\text { Rubber accelerators, potassium dichromate, cobalt, adhesives (PTBFR*, colophony), } \\
\text { textile dyes }\end{array}$ & $\begin{array}{l}\text { Friction } \\
\text { Occlusion } \\
\text { Maceration from sweating }\end{array}$ \\
\hline
\end{tabular}

*PTBFR: p-tert-butylphenol formaldehyde resin

**N-isopropyl-n'-phenyl-p-phenylenediamine

of patients with occupational ACD had positive reactions to only NACDG screening series allergens, $13.1 \%$ also reacted to $\geq 1$ supplemental allergen(s), and $5.2 \%$ only had positive reactions to $\geq 1$ supplemental allergen(s). For patients tested to supplemental allergens, top sources were adhesives/glues/bonding agents, hair dyes, gloves, coatings, moisturizers/lotions/creams, and metalworking fluids [5•]. Testing with supplemental allergens is recommended in cases of OCD, given the specific contacts that may be encountered in the workplace. For example, testing with a rubber series has greater sensitivity than patch testing to actual workplace gloves [25•]. Supplemental series of allergens are available for common occupations, such as hairdressers and dental workers.

Commercially produced standardized patch test extracts are not available for a number of potentially allergenic workplace materials. Additive value of testing with patients' own products has been proven in general [26] as well as for specific types of products such as leave-on cosmetics [25•], epoxy resins [27], isocyanates [28], and metalworking fluids [29] to name a few. Therefore, many patients with suspected OCD should be considered for custom testing. This involves patch testing patients with products from work including chemicals, hand cleansers, and personal protective equipment, as well as their personal care products [26].

\section{Testing with Workplace Materials}

Substances not available for testing in standardized series will be identified by reviewing the SDS [14]. Products may be requested from the workplace and sent to the clinic directly. Suitable ranges of concentrations and vehicles can be obtained by consulting a comprehensive reference manual (DeGroot patch testing) [30]. Unidentified substances as well as known irritants should not be tested due to the risk of inducing local or potentially even systemic adverse reactions [30]. Workplace substances should be diluted appropriately by an interested and experienced chemist or by a compounding pharmacist. Guides for preparation of custom allergens are available, detailing the necessary equipment, dilution methods, and role for extraction [31]. With proper dilutions, most workplace materials may be tested with classic patch testing (occlusive testing). Other methods of testing custom materials should be considered in specific settings (Table 5) [32-37]. In research settings and for publication purposes, testing controls are necessary to confirm the validity of the reaction and to eliminate the possibility of an irritant reaction. Although confirmation of test results using these methods are ideal, it is often not feasible in the usual clinical setting. In the authors' opinion, the inability of testing controls should not prevent custom testing. 
Table 5 Methods for testing custom materials from work

\begin{tabular}{|c|c|c|}
\hline Methods & Description & Indications \\
\hline $\begin{array}{l}\text { Repeat open application test (ROAT) } \\
\text { [34] }\end{array}$ & $\begin{array}{l}\text { Test substances, as is, are applied twice daily for } \\
7 \text { days to the outer aspect of the upper arm, } \\
\text { antecubital fossa, or back skin (scapular area) on } \\
\text { a } 1 \times 1 \mathrm{~cm}^{2} \text { or larger area. The patient is asked to } \\
\text { stop the application of the test substance(s) when a } \\
\text { reaction is noted }\end{array}$ & $\begin{array}{l}\text {-If patch test is negative and still have a strong } \\
\text { suspicion of ACD } \\
\text {-To verify the allergic nature of the patch test } \\
\text { result } \\
\text { - To determine both irritant and allergic } \\
\text { responses to materials or products suspected } \\
\text { of producing contact dermatitis in particular } \\
\text { patients }\end{array}$ \\
\hline Usage test, provocative use test [35] & $\begin{array}{l}\text { Variant of the ROAT } \\
\text { Reflective of real-life exposure to an allergen through } \\
\text { the uses of only one product, twice a day for } \\
7 \text { days, on the previously affected skin. The patient } \\
\text { is asked to stop the application of the product when } \\
\text { a reaction is noted }\end{array}$ & $\begin{array}{l}\text { To determine both irritant and allergic } \\
\text { responses to materials or products suspected } \\
\text { of producing contact dermatitis in particular } \\
\text { patients }\end{array}$ \\
\hline Open test (use test) & $\begin{array}{l}\text { A product, as is or diluted, is placed onto the skin of } \\
\text { the volar forearm and allowed to spread up to an } \\
\text { area of } 5 \times 5 \mathrm{~cm}^{2} \text {. No occlusion is used }\end{array}$ & $\begin{array}{l}\text {-Screen (first test) for unknown substances } \\
\text {-Verify doubtful patch test reactions }\end{array}$ \\
\hline Semi-open test [36] & $\begin{array}{l}\text { A product, as is or diluted, is dropped onto the skin } \\
\text { of the volar forearm or the back and allowed to } \\
\text { spread up to a surface of } 5 \times 5 \mathrm{~cm}^{2} \text {. Area is covered } \\
\text { by a nonocclusive tape (e.g., micropore) when they } \\
\text { have dried off ( } 5-10 \mathrm{~min})\end{array}$ & $\begin{array}{l}\text {-Screen (first test) for unknown substances } \\
\text {-When irritancy under occlusion is suspected } \\
\text {-When direct skin contact with product } \\
\text { Via normal work processes (cleaning products) } \\
\text { Accidental (soluble oils, paints) }\end{array}$ \\
\hline Strip patch test [37] & $\begin{array}{l}\text { Variant of conventional patch testing. Consists of } \\
\text { "stripping" the stratum corneum } 8-12 \text { times with } \\
\text { a cellophane tape before applying the allergens in } \\
\text { the usual way }\end{array}$ & For allergens with poor skin penetration \\
\hline $\begin{array}{l}\text { Scratch patch test (prick chamber test) } \\
\text { [36] }\end{array}$ & $\begin{array}{l}\text { Variant of conventional patch testing. Consists of } \\
\text { scarification of the skin with a 30-gauge needle in } \\
\text { a parallel straight diagonal pattern or in a crisscross } \\
\text { pattern before applying the allergens in the usual } \\
\text { way }\end{array}$ & $\begin{array}{l}\text {-For allergens with poor skin penetration } \\
\text {-Suspicion of protein contact dermatitis }\end{array}$ \\
\hline
\end{tabular}

\section{Establishing a Diagnosis of Occupational Dermatitis}

Diagnosing OCD may prove to be difficult as there are no characteristic clinical or histological features. Mathias [38] proposed 7 criteria for establishing occupational causation and occupational aggravation of contact dermatitis (ACD or ICD) (Table 6). Positive answers to 4 or more of the 7 criteria are considered sufficient to establish occupational causation. Clear yes or no answers are not always possible in complicated cases. Mathias criteria have been validated to provide a likelihood of $50 \%$ or more in establishing a connection between contact dermatitis and occupation. They thus may be helpful in medicolegal cases [39].

\section{Return to Work}

Management of OCD may require changes in workplace practices to reduce worker exposure to the causative agents and improve skin care practices. Effective communication between the physician, worker, workplace, and insurer is a key principle that supports successful return to work (RTW).
Table 6 Mathias criteria for establishing occupational causation and aggravation of contact dermatitis [38]
Is the clinical appearance consistent with contact dermatitis?

Are there workplace exposures to potential cutaneous irritants or allergens?

Is the anatomic distribution of dermatitis consistent with the form of cutaneous exposure in relation to the job task?

Is the temporal relationship between exposure and onset consistent with contact dermatitis?

Are non-occupational exposures excluded as likely causes?

Does avoiding exposure lead to improvement of the dermatitis?

Do patch tests or provocation tests implicate a specific workplace exposure? 
Clear recommendations for the workplace are indispensable. A skin-specific "workplace prescription" has been developed and tested for practicality in real-life settings [40]. It provides specific advice to the worker and the employer on recommended preventive strategies including work restrictions to facilitate modified work, choice of PPE, appropriate hand hygiene, and treatment. A graduated trial of RTW with ongoing skin monitoring to detect early recurrence has been used successfully [41].

\section{Emerging Topics in OCD}

The COVID-19 pandemic has been a pervasive force in the year 2020, and the effects of this pandemic have been a major theme in occupational health. A systematic review of facial occupational dermatoses due to personal protective equipment revealed that ACD and ICD are most common, followed by acneiform eruptions and contact urticaria [42•]. Multiple publications describe and analyze the cutaneous side effects of PPE and intensified hand hygiene, consistently finding that OCD is the predominant observed reaction [43-45]. With respect to hand dermatitis, alcohol-based hand sanitizers with moisturizers have the least sensitizing and irritancy potential compared to soaps and synthetic detergents [46]. In a study in health care professionals, the provision of recommendations which included specific product names was found to be superior to general recommendations alone [47].

\section{Conclusion}

OCD is a multifaceted condition with significant consequences for affected workers and their families, employers, and insurers. A methodical and individualized approach to the patient with OCD should ensure timely and accurate diagnosis(es). Appropriate management of OCD can then be instituted, with better outcomes for the worker as well as for all parties involved.

\section{Compliance with Ethical Standards}

Human and Animal Rights and Informed Consent This article does not contain any studies with human or animal subjects performed by any of the authors.

\section{References}

\section{Papers of particular interest, published recently, have been highlighted as:}

- Of importance
1. Ale IS, Maibach HI. Irritant contact dermatitis. Rev Environ Health. 2014;29(3):195-206. https://doi.org/10.1515/ reveh-2014-0060.

2. Skotnicki S. Allergic contact dermatitis versus irritant contact dermatitis. Discussion paper prepared for The Workplace Safety and Insurance Appeals Tribunal of Ontario, Canada. May 2008, Revised November 2014.

3. Diepgen TL \& Coenraads PJ. Occupational contact dermatitis. In Rustemeyer T, Elsener P, John SM, Maibach HI (Eds.), Kanerva's occupational dermatology $\left(2^{\text {nd }}\right.$ ed., pp. 51-58). Springer-Verlag Berlin Heidelberg 2012. https://doi.org/10.1007/ 978-3-642-02035-3

4. Holness DL. Occupational dermatosis. Curr Allergy Asthma Rep. 2019 19(9):42.

5. DeKoven JG, DeKoven BM, Warshaw EM, Mathias CGT, Taylor JS, Sasseville D, et al. Silverberg JI, Atwater AR, Reeder MJ, D Linn Holness. Occupational contact dermatitis: retrospective analysis of North American Contact Dermatitis Group Data, 2001 to 2016. J Am Acad Dermatol. 2021 Mar 19;S0190-9622(21)00591-0. https://doi.org/10.1016/j.jaad. 2021.03.042. Online ahead of print. *Current NACDG data on occupational contact dermatitis.

6. Lampel HP, Powell HB. Occupational and hand dermatitis: a practical approach. Clin Rev Allergy Immunol. 2019 56(1):60-71.

7. Bains SN, Nash P, Fonacier L. Irritant contact dermatitis. Clin Rev Allergy Immunol. 2019 56(1):99-109. *Comprehensive review on irritant contact dermatitis.

8. Friis UF, Menné T, Schwensen JF, Flyvholm MA, Bonde JP, Johansen JD. Occupational irritant contact dermatitis diagnosed by analysis of contact irritants and allergens in the work environment. Contact Dermatitis. 2014 71(6):364-70.

9. Rusca C, Hinnen U, Elsner P. 'Patient's delay' - analysis of the preclinical phase of occupational dermatoses. Dermatology. 1997;194:50-2.

10. Keegel T, Cahill J, Noonan A, Dharmage S, Saunders H, Frowen $\mathrm{K}$, et al. Incidence and prevalence rates for occupational contact dermatitis in an Australian suburban area. Contact Dermatitis. 2005;52(5):254-9.

11. Nurmohamed S, Bodley T, Thompson A, Holness DL. Health care utilization characteristics in patch test patients. Dermatitis. 2014;25:268-72.

12. Nichol K, Copes R, Kersey K, Eriksson J, Holness DL. Screening for hand dermatitis in healthcare workers: comparing workplace screening with dermatologists' photo screen. Contact Dermatitis. 2019;80:374-81.

13. Nicholson PJ, Llewellyn D, English JS; Guidelines Development Group. Evidence-based guidelines for the prevention, identification and management of occupational contact dermatitis and urticaria. Contact Dermatitis. 2010 Oct;63(4):177-86.

14. Alfonso JH, Bauer A, Bensefa-Colas L, Boman A, Bubas M, Constandt $\mathrm{L}$, et al. Minimum standards on prevention, diagnosis and treatment of occupational and work-related skin diseases in Europe - position paper of the COST Action StanDerm (TD 1206). J Eur Acad Dermatol Venereol. 2017;31(Suppl 4):31-43.

15. Nicholson PJ. Occupational contact dermatitis: known knowns and known unknowns. Clin Dermatol. 2011 May-Jun;29(3):325-30.

16. Regional Atlas of Contact Dermatitis. Edited by Robin Lewallen and Steven R. Feldman. The Dermatologist. https://www.the-dermatologist. $\mathrm{com} / \mathrm{sites} /$ default/files/Regional\%20Atlas\%20of\%20Contact\% 20Dermatitis\%20Book_lr.pdf

17. Staser K, Ezra N, Sheehan MP, Mousdicas N. The beak sign: a clinical clue to airborne contact dermatitis Dermatitis Mar-Apr. 2014;25(2):97-8.

18. Jacob SE, Breithaupt AD. An important difference between "exposed" and "photodistributed" underscores the importance of identifying common reactions. J Clin Aesthet Dermatol. 2009 2(9):44-5. 
19. Zirwas MJ. Contact dermatitis to cosmetics. Clin Rev Allergy Immunol. 2019 56(1):119-28.

20. Pesonen M, Jolanki R, Larese Filon F, Wilkinson M, Kręcisz B, Kieć-Świerczyńska M, et al. Uter W; ESSCA network. Patch test results of the European baseline series among patients with occupational contact dermatitis across Europe - analyses of the European Surveillance System on Contact Allergy network, 20022010. Contact Dermatitis. 2015 Mar;72(3):154-63.

21. Antonov D, Kleesz P, Elsner P, Schliemann S. Impact of glove occlusion on cumulative skin irritation with or without hand cleanser-comparison in an experimental repeated irritation model. Contact Dermatitis. 2013 68(5):293-9.

22. Yu J, Chen JK, Mowad CM, Reeder M, Hylwa S, Chisolm S, et al. Occupational dermatitis to facial personal protective equipment in health care workers: a systematic review. J Am Acad Dermatol. 2021;84(2):486-94.

23. Nguyen HL, Yiannias JA. Contact dermatitis to medications and skin products. Clin Rev Allergy Immunol. 2019 56(1):41-59.

24. DeKoven JG, Silverberg JI, Warshaw EM, Atwater AR, Reeder MJ, Sasseville D, et al. North American Contact Dermatitis Group patch test results: 2017-2018. Dermatitis. 2021;32(2):11123. *Current NACDG patch test results.

25. Schubert S, Geier J, Skudlik C, Reich A, Hansen A, Buhl T, et al. Relevance of contact sensitizations in occupational dermatitis patients with special focus on patch testing of workplace materials. Contact Dermatitis. 2020 Dec;83(6):475-486. *Important data on occupational dermatitis and investigation.

26. Slodownik D, Williams J, Frowen K, Palmer A, Matheson M, Nixon R. The additive value of patch testing with patients' own products at an occupational dermatology clinic. Contact Dermatitis. 2009 61(4):231-5.

27. Houle MC, Holness DL, DeKoven J, Skotnicki S. Additive value of patch testing custom epoxy materials from the workplace at the occupational disease specialty clinic in Toronto. Dermatitis. 2012 Sep-Oct;23(5):214-9.

28. Burrows D, Houle MC, Holness DL, DeKoven J, Skotnicki S. Patch testing custom isocyanate materials from the workplace. Dermatitis. 2015 Mar-Apr;26(2):94-8.

29. Geier J, Uter W, Lessmann H, Frosch PJ. Patch testing with metalworking fluids from the patient's workplace. Contact Dermatitis. 2004 51(4):172-9.

30. de Groot, AC. Patch Testing, $4^{\text {th }}$ Edition: Test concentrations and vehicles for 4900 chemicals. Wapserveen: acdegroot publishing. 2018.

31. Niklasson Bo J. In Guin JD. Practical contact dermatitis. A handbook for the practitioner. 1995.

32. Lachapelle JM, Maibach HI. Additional testing procedures and spot tests. (2012, $3^{\text {rd }}$ Edition) In: Lachapelle JM \& Maibach HI (Eds) Patch testing and prick testing, a practical guide official publication of the ICDRG. Springer Heidelberg Dordrecht London New York

33. Marks JG, Anderson BE, \& DeLeo VA. (2016, $4^{\text {th }}$ Edition) Contact \& occupational dermatology. Jaypee Brothers Medical Publishers.
34. Hannuksela M, Salo $H$. The repeated open application test (ROAT). Contact Dermatitis. 1986 14(4):221-7.

35. Christensen OB, Möller H. External and internal exposure to the antigen in the hand eczema of nickel allergy. Contact Dermatitis. 1975 1(3):136-41.

36. Dooms-Goossens A. Patch testing without a kit. In: Guin JD, editor. Practical Contact Dermatitis. New York: McGraw Hill; 1995. p. 63-74.

37. Dickel H, Kamphowe J, Geier J, Altmeyer P, Kuss O. Strip patch test vs. conventional patch test: investigation of dose-dependent test sensitivities in nickel- and chromium-sensitive subjects. J Eur Acad Dermatol Venereol. 2009 Sep;23(9):1018-25.

38. Mathias CGT. Contact dermatitis and workers compensation: criteria for establishing occupational causation and aggravation. $\mathbf{J}$ Am Acad Dermatol. 1989;20:842-8.

39. Ingber A, Merims S. The validity of the Mathias criteria for establishing occupational causation and aggravation of contact dermatitis. Contact Dermatitis. 2004 51(1):9-12.

40. Kudla I, Houle MC, Velykoredko Y, Gomez P, DeKoven J, Skotnicki $\mathrm{S}$, et al. Introducing a "workplace prescription" to facilitate return to work for workers with occupational contact dermatitis. J Cutan Med Surg. 2017 Nov/Dec;21(6):573-575.

41. Chen J, Gomez P, Kudla I, DeKoven J, Holness DL, Skotnicki S. Return to work for nurses with hand dermatitis. Dermatitis. 2016 Sep-Oct;27(5):308-12.

42.• Yu J, Chen JK, Mowad CM, Reeder M, Hylwa S, Chisolm S, et al. Occupational dermatitis to facial personal protective equipment in health care workers: a systematic review. J Am Acad Dermatol. 2021 84(2):486-94. * Comprehensive review of facial PPE adverse effects.

43. Mushtaq S, Terzi E, Recalcati S, Salas-Alanis JC, Amin S, Faizi N. Cutaneous adverse effects due to personal protective measures during COVID-19 pandemic: a study of 101 patients. Int J Dermatol. 2021 60(3):327-31.

44. Burns ES, Pathmarajah P, Muralidharan V. Physical and psychological impacts of handwashing and personal protective equipment usage in the COVID-19 pandemic: a UK based crosssectional analysis of healthcare workers. Dermatol Ther. 2021 Feb 16:e14885.

45. Rundle CW, Presley CL, Militello M, Barber C, Powell DL, Jacob SE, et al. Hand hygiene during COVID-19: Recommendations from the American Contact Dermatitis Society. J Am Acad Dermatol. 2020;83(6):1730-7.

46. Chernyshov PV, Kolodzinska L. Prospective study on hand dermatitis in nurses and doctors during COVID-19 pandemic and its improvement by use of adopted recommendations of the European Academy of Dermatology and Venereology Task Force on Contact Dermatitis. Dermatol Ther. 2020 Nov;33(6):e14396.

47. Xie Z, Yang YX, Zhang H. Mask-induced contact dermatitis in handling COVID-19 outbreak. Contact Dermatitis. 2020 83(2):166-7.

Publisher's Note Springer Nature remains neutral with regard to jurisdictional claims in published maps and institutional affiliations. 